\title{
Aspects of Digital Documents Archiving by the Organizations in the Czech Republic in Context of the EU eGovernment
}

\author{
Stanislava Simonova \\ Institute of System Engineering and Informatics \\ University of Pardubice \\ Pardubice, Czech Republic \\ Stanislava.Simonova@upce.cz
}

\author{
Meseret Yihun AMARE \\ Institute of System Engineering and Informatics \\ University of Pardubice \\ Pardubice, Czech Republic \\ yihunm@gmail.com
}

\begin{abstract}
Data in the company are the base and also product of all done procedures, on one side the commercial, on the other side the contact with public administration. Data are associated into the documents which come through several phases of the life cycle according to the organization's needs. The organization handles with the documents (digital or analogue) and in connection to it there might appear some questions: Is the digital document equal to the analogue? How to keep digital documents so that they will be readable for all its life cycle? How to secure digital documents against changing (also not wanted), against falsification or damage? The legislation also influence the companies behavior, which means the influence how the documents are dealt with. Legislative definition is solved at the national levels, but also within the $\mathrm{EU}$, where the effort is to set the environment for electronic trust services. The aim of this text is to chart the present situation about handling with documents in the company, especially the documents archiving, to show the problematic aspects and to describe also possible ways of solution.
\end{abstract}

\section{Keywords-Archiving; Digital document; eIDAS Regulation}

\section{INTRODUCTION}

Documents and the process of the dealing with them belongs to everyday procedure in every company. The term 'document' is defined in the Czech law in the Act No. 499/2004 Coll. on Archives and Record Management [4] [14]. According to this Act, the document is every recorded information (written, pictorial, acoustical or other), in the analogue or digital form, which was created by the originators or it was delivered to the them.

Public institution (and in special occasions also private people) have the obligation to keep their documents and also to enable the selection of the documents to be archived. According to $\$ 3-5$, the documents determined to be archived are selected on the basis of the public interest considering the special meaning. The selection is done by the relevant Provincial Archives and those documents are then kept for ever. The documents after their creation are usually put into registry and there they stay for a specific time. All documents, which are referred to specific things are connected to one file and they are labelled by the same reference number. According to $\S 65$, the documents in analogue form are connected together physically, the digital documents are connected by metadata.

The documents can be converted, i. e. are transferred from paper form to the data form or to data file and vice versa, which is defined in the Act No. 300/2008 Coll., on electronic acts and documents authorized conversion, eGovernment Act [3]. According to $\$ 22$ and 23, the conversion can be done by public authority, the converted document have then the same legal effects as the original one.

The important EU regulation, which influences the digital documents, is the Regulation EU No 910/2014 of the European Parliament and of the Council of 23 July 2014 on electronic identification and trust services for electronic transactions in the internal market and repealing Directive 1999/93/EC. This Regulation is called in short eIDAS [13]. The eIDAS Regulation provides a predictable regulatory environment to enable secure and seamless electronic interactions between businesses, citizens and public authorities. In this regard, the eIDAS Regulation [12]:

- creates the European internal market for electronic trust services - namely electronic signatures, electronic seals, time stamp, electronic delivery service and website authentication - by ensuring that they will work across borders and have the same legal status as traditional paper based processes,

- ensures that people and businesses can use their own national electronic identification schemes to access public services in other EU countries where electronic identification schemes are available.

European legislation is superior to the national one, therefore the changes in the Czech legislation had to be done on the basis of this eIDAS Regulation. The changes in the Czech legislation are - Act no 297/2016 Coll. - on trust services for electronic transactions [2], and Act no 298/2016 Coll., amending some acts in relation to the adoption of Trust Services Act. Mentioned legal rules brought the changes mainly into the area of electronic identification and authenticity. 


\section{TECHNOLOGICAL TOOLS FOR DEALING WITH DIGITAL DOCUMENTS}

Among the basic technological tools for dealing with digital documents belong - Electronic Signature, Electronic Seal and Electronic Time Stamp. These tools are based on the similar technological solutions with using hash function, asymmetric cryptography encryption, digital certificate etc. The tools are differed by the usage:

- Electronic signature: Electronic signature provides unique identification data, which connects it to the signing person. Signing person has the exclusive data usage for its electronic signature. Also the change of the data can be recognized after signing.

- Electronic seal: Data labelled by the seal has the proved integrity of the data and rightness of the origin. The seal is used where the precise personalization is not needed.

- Electronic time stamp: The time stamp confirms the rightness of the date and time and integrity of the data. Using the stamp does not say anything about the document origin. It is only the information about the existence of the document in the specific time and that the document was not changed from that time.

Among other technological solutions belong usage of the recommended data formats. Data formats for the digital documents are defined in Ministerial Decree No. 259/2012 Coll., on the details of the file service performance, as amended, § 23 [8].

The main format for the long-lasting documents archiving is the world accepted archived format PDF/A. This format comes out of the format PDF (Portable Document Format), which is published as the standard ISO 32000. Archived version of the format PDF/A is defined by the rule ISO 19005. The present version enables to use PDF/A file as the container for other content [11].

Other standardized formats suitable for archiving are defined e.g. - for static pictorial documents (PNG Portable Network Graphics, ISO/IEC 15948; TIFF Tagged Image File Format, revision 6 uncompressed; JPEG File Interchange Format, JPEG/JFIF, ISO/IEC 10918), for dynamic pictorial documents (MPEG-2 Moving Picture Experts Group Phase 2, ISO/IEC 13818; MPEG-1 Moving Picture Experts Group Phase 1, ISO/IEC 11172; GIF Graphics Interchange Format), for acoustic documents (MP2 - MPEG-1 Audio Layer2; MP3 MPEG-1 Audio Layer3; WAV Waveform audio format; PCM Pulse-code modulation), for databases (XML Extensible Markup Language Document, where the parts of the handed document in data format XML is the description of its structure using the scheme XML or DTD Document Type Definition).

Disadvantage of some of the formats compared to PDF is the impossibility to insert the data signature straight into the document (internal electronic signature); electronic signature is realized in case of need by the application of the separate digital signature (external digital signature).

\section{DEALING WITH DIGITAL DOCUMENTS IN THE COMPANY}

The digitalization refers to many companies, these reasons are important in the company - to set and secure the procedures for dealing with the digital documents positively. Digital document management and document archiving solves the main questions, see Figure no 1 .

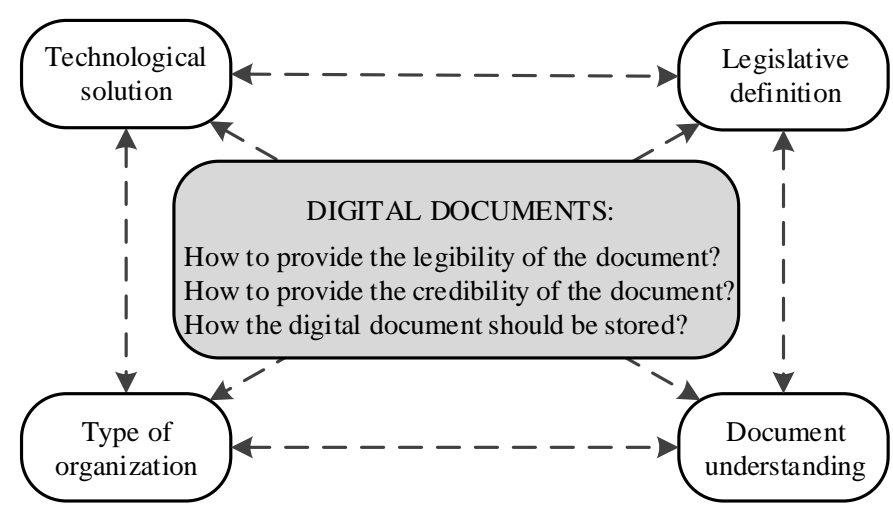

Figure 1. Digital documents archiving; source: own

Solution of the above mentioned questions (see Figure no 1.) is based on the combination of three aspects:

- understanding the digital documents,

- legislative definition,

- technological solution.

\section{A. Understanding the Digital Documents}

It seems that the technological solution is the most important aspect. However, the aspect of 'understanding the documents' plays also an important role.

The paper document, old several decades (or hundreds years) is primarily considered to be the right one, although the originator of the document is not alive any more. When there are some doubts about the authenticity of the paper document the proof is done (e.g. chemical, physical or graphological). Such confidence at the digital document obviously does not exist. This arises from the present technological possibilities. Comparing the basic characteristics of the analogue and digital documents are in the Table no. 1.

Legislative aspect is important mainly at the public administration companies, because all the public steps by the public subjects have to be done according to the law. Commercial sphere does not have usually problems with legal rules, which modify dealing with the documents. The companies have to follow the rules set by the law only in connection to the communication with public administration.

\section{B. Legibility of the Documents}

Legibility of the digital documents can be provided by the tools combination - standardized formats, conversions among formats, conversion among forms of the documents.

Standardized formats: Legibility of the digital documents in the future (independent on the specific HW and SW equipment) can be provided only for the documents, which are 
created by standardized formats. Present accepted formats can lose its support, in consequence of the fundamental technological or legislative change. Therefore the technological and legislative development must be monitored and in case of the change it is necessary to convert the digital document into the different, supported format.

TABLE I. COMPARISON OF THE BASIC CHARACTERISTICS OF THE ANALOGUE AND DIGITAL DOCUMENTS; (SOURCE: OWN, BASED ON [16])

\begin{tabular}{|l|l|l|}
\hline & ANALOGUE Documents & DIGITAL Documents \\
\hline $\begin{array}{l}\text { Content of } \\
\text { the original }\end{array}$ & $\begin{array}{l}\text { Content is bond by the } \\
\text { carrier. }\end{array}$ & $\begin{array}{l}\text { Information (content) is } \\
\text { independent on the data } \\
\text { carrier or format. }\end{array}$ \\
\hline $\begin{array}{l}\text { Original } \\
\text { and copy }\end{array}$ & $\begin{array}{l}\text { The original and the copy } \\
\text { can exist and it is possible } \\
\text { to differentiate them. }\end{array}$ & $\begin{array}{l}\text { It is not possible to } \\
\text { differentiate the original } \\
\text { and the copy. }\end{array}$ \\
\hline Authenticity & $\begin{array}{l}\text { Characteristics of the } \\
\text { documents (verifying the } \\
\text { authenticity) disappears } \\
\text { with the physical } \\
\text { characteristics of the } \\
\text { document. }\end{array}$ & $\begin{array}{l}\text { The authenticity of the } \\
\text { document is given by } \\
\text { metadata and their virtual } \\
\text { characteristics. }\end{array}$ \\
\hline $\begin{array}{l}\text { Technology } \\
\text { of archiving }\end{array}$ & $\begin{array}{l}\text { Technological possibility } \\
\text { to keep physical and } \\
\text { chemical characteristics } \\
\text { of the document. } \\
\text { Archiving of the paper } \\
\text { documents is the field, } \\
\text { which exists thousands of } \\
\text { years. }\end{array}$ & $\begin{array}{l}\text { Technology of the data } \\
\text { legibility keeping and } \\
\text { storing of the virtual } \\
\text { characteristics of the } \\
\text { documents. Archiving the } \\
\text { digital documents exists } \\
\text { only several decades, it is } \\
\text { much more dynamic and } \\
\text { unstable. }\end{array}$ \\
\hline
\end{tabular}

Conversion among the formats: Digital documents can be created by technical tools such as - recording device, SW robots, information systems, measuring devices etc. Various data files are created, their formats are not always standardized and they are not suitable for long-term archiving. Therefore the documents determined for the long-term archiving must be converted into standardized formats.

Conversion among the documents formats: Conversion among the documents formats means the conversion among analogue and digital documents. Analogue documents can be digitalized, i.e. it is possible to convert them into digital documents. Scanning methods are used for this conversion. And also the digital documents can be converted into analogue form, mainly by printing the documents. Resultant analogue documents at the text documents carries the information about the original document; at the pictorial documents, the big amount of the preserved data depend on the differentiate ability of the input device. The authorized documents conversion in the Czech Republic is a paid service done by the Czech POINT. This service is accessed without payment for organizations of the public administration (it is the conversion 'ex officio').

\section{Documents Authenticity}

Authenticity of the digital documents can be provided by the tools for signature allowance, seal and time stamp. The eIDAS Regulation defines the Advanced Electronic Seal and Qualified Electronic Time Stamp, and there are more variants for the digital signature - Qualified Electronic Signature, Advanced Electronic Signature and Electronic Signature. A qualified electronic signature is an advanced electronic signature with a qualified digital certificate that has been created by a qualified signature creation device [7] [15]. Qualified Electronic Signature is the highest form of the signature and the eIDAS Regulation understands this signature to be the same as personally handwritten.

Advanced Electronic Seal can be used only at the documents, where the company is the originator itself; also the body corporates must use the seal in communication with the public authority.

New legal rules mean the end of the important rule, which is asserted in the Czech Republic. It is so called - legal presumption of its authenticity and integrity, which was characterized in $\$ 69$ a par. 5 Act No. 499/2004 Coll. on Archives and Record Management. It is necessary to mention, that the professional public has not explicit opinion about this rule. The explanation of the rule was, that if the digital documents were labelled with electronic signature (or seal) and also if this documents were labelled by time stamp at the time of the signature, then the digital documents is thought to be 'always' right also when the time validity of the tools expire. Electronic signature is issued for 12 months, electronic seal is issued for 12 months, the validity of the time stamp is from 3-5 years. Supporters of the approach deduced the solution on the basis of 'presumption of its authenticity', which means that the only time stamp on the document is enough for arbitrary length of time of the documents' existence and the practice of the over-stamping is not necessary. Opponents of the approach suggested gradually over-stamping the documents in the repeated intervals.

Deletion of the approach 'presumption of its authenticity' means that now it is necessary to care of the electronic documents actively, i.e. label the documents by other time stamps in the regular intervals. [15]

The eIDAS Regulation has also the specific effect on the system of the data inboxes (ISDS), which is used in the Czech Republic for a safe electronic communication firstly within the public administration and also with public administration. ISDS integrates three services: e-signature, e-identity, edelivery. The user is logged in to ISDS and by this the identity is proved; the user then sends the documents and by this tool the safe delivery to the recipient is done. Sent documents do not have to be signed, because the sender is identified by the logging in and therefore it is identified in the system ISDS. The eIDAS Regulation deals with these three services strictly separately. It is expected that according to eIDAS will be also made some operational changes in ISDS [10]

\section{Storing and Archiving of the Documents}

Life cycle of every document begins at the phase of creation, followed by the phase of using the document, then the phase of the assessment of the document if or how the document will be used in the future. If the decision is made that the documents are better keep for a longer time, it goes into the phase of archiving. Otherwise, it is shredded. 
The period for archiving of the documents are set by the law, in the Czech Republic it is about - the accounting documents for 5 years, tax documents for 10 years, agreements for 10 years, documents about salaries/wages and others connected to them for 30 years, the archival records for ever.

After the length of an archiving time, the documents should be destroyed. Destroying of the analogue documents is done by the physical shredding, which means that the original documents will not exist any more and some of the copies can exists. Destruction of the digital documents is done by deleting them from the data storage (e.g. from the electronic Record Management System), i.e. that the copy of the document is destroyed. However, copy of the other document (the same as the destroyed one) can exist for example in the backup data.

The aim of the documents archiving is not only the storing them, but also the accessibility of the documents. At the analogue documents, content (of the information) is tightly connected with carrier and this document degrades by the time by the influence of the environment. Archiving of the analogue documents means to archive original form and content, which means the documents preservation in as good quality as possible. Lifetime of the analogue documents have the same characteristics as the physical carrier. Techniques of the analogue documents archiving are known for several thousands of years and now they are improving so the degradation of the documents will be as low as possible. The lifetime of the carrier for the analogue documents is much longer than the lifetime of the carrier of the digital data, e.g. paper has the lifetime of hundreds of years, film strip has the lifetime of about 300 years, DVD has the lifetime of 10 to 100 years, hard disk has the lifetime of 3-10 years [6]. The question is certainly connected to it: Are the present carriers with digital data going to be applicable in the future HW-SW devices? However, the present digital time means the increasing volume of the digital data.

Archiving of the digital documents cannot solve the choice of carrier of the information, but storage of the information (content) itself [5]. It is not a problem - copy the data and change the different forms of carrier, create the backup copies and distribute them at the various storage. All these activities are electronic and in this case the archiving of the documents is much easier. There are, however, new problems, which these forms of the documents bring and they are above mentioned ensuring the documents readability and credibility. They need regular maintenance from these reasons of the archived digital documents by checking the lifetime of the data carrier, compatibility of the format and validity of the electronic signature and time stamp.

Archiving of the documents: The documents evaluated as an archival records are placed in the archive of the organization or they are handed to a long-term archiving at the relevant superior archive. This superior archive, which stores the analogue documents, must meet the conditions set by the law, especially constructional and technical. Archive, which stores the digital documents is a data storage. If the archive is kept within the Record Management System, then this storage must meet the national standard for the electronic systems of the records management. The result of the destruction management means that it is decided about the archival choice for long-term archiving. The documents determined for the long-term archiving are handed to the Provincial Archives or National Digital Archive.

\section{E. Storage of the Digital Documents}

The specific solution for the data storage is depended on the characteristics of the organization, i.e. the size, the needs, the economical situation and the type of the organization; in other words if it is the commercial company or the public administration.

The commercial organizations use very often 'its own data storage'. The simple storage can be realized by the form of documents saved on the PC, wide storage are managed by the Record Management System. If the documents are for archiving and if these documents are in the data storage without Record Management System and without transaction history, then the documents are necessary to sign electronically or put the seal and repeatedly over-stamp by the time stamp because of the authenticity of the documents. At this solution there are not defined any standards; storages are created according to the needs and possibilities of every specific organization.

The public authorities must use the Electronic Record Management System. This system is operated by the own storage or by the cloud solution. The authenticity of the stored documents is provided by transaction history, which is recorded in transaction log. Thanks to it, it is possible to provide authenticity of documents delivered by ISDS system, i.e. these documents do not have to be electronically signed.

The present trend represents Commercial Cloud Solutions. The providers of these services guarantee storing the digital documents at one place, protect them all the time, with regular maintenance of the storage as well as the documents themselves, including the long-term credibility secure [9]. The advantage of this storage is that the services are accessible, strong and robust for the companies which do not have their own finance for their own solution. The authenticity of the saved documents is secured by the over-stamping.

\section{ARCHIVING OF THE DIGITAL DOCUMENTS FROM THE POINT OF TIME AND TYPE OF THE ORGANIZATION}

The work with digital documents relies on the technological tools within the legislative definition. It is possible to say, that there is a big difference between the commercial companies and public administrations. Commercial companies have a different approach towards the documents management than the public administration.

The public administration have to follow the law. It has to lead the Records Management, has to sign the digital documents by electronic signature (or electronic seal) and stamp by the time stamp. It has to communicate electronically. The archive for the analogue documents or data storage for digital documents have to follow the special rules. Another duty of the public authority is to hand archival reports for a long-term archiving to the National Archive. All these duties need complex, sophisticated and elaborate system of work with 
the documents. According to the permanent department and to non-stop changes (at the field of legislative, as well as at the field of technology), the public administration subject is forced to update often their HW and SW equipment and the process itself.

Commercial sphere does not have the essential problem with legal rules, which edits the work with documents. Only while the communication with public administration have to follow the rules set by the law. In other cases the company can create its own way of documents. It can actually do everything, what is not forbidden by the law. As an example, we can show the invoice, which is the tax document. The tax document is the written document, which meets the conditions set in the law in Act No. 235/2004 Coll., Value Added Tax Act [1]. According to the law, 'tax document can have the written or electronic form; tax document can be in electronic form in case that it is set and delivered electronically; the person who the product or service is for have to agree with electronic form'. The law does not require the signature or stamp in case of the invoice in case of the digital document any electronic signature or time stamp is not required either. The company decides itself which form is more suitable for it. The contact with the commercial sphere is understood as disposal matter in the meaning of order-buy-pay. The private person has the document for the time of warranty period, company then for 10 years. Every company has to decide if the tax documents will be printed and then archived as analogue documents or store them digitally. Law orders the companies how long the documents must be archived, but do not order the form and how to do it. However, the company is responsible for a possible loss, damage or destruction of the documents.

\section{A. Investigation in the Selected Companies}

The investigation was done in two selected companies, in the commercial company (engineering and developer company with about 500 employees) and the public authority (town hall of municipality with extended powers). The investigation in both companies were oriented on - overall dealing with documents, readability and credibility security, way of documents storage, solution of the long-term archiving.

These realities were found by analysing the ways of dealing with documents in the commercial company:

Beginning of the legislative rules connected to the eIDAS did not have the fundamental influence on the processing with documents in the company. The organization does not have a comprehensive Record Management System and use several systems for saving digital documents (commercial information systems, e-mails, servers, structured data storage). Saved digital documents are labelled by qualified electronic signature or are sent via ISDS system (e.g. when communicate with the public authorities). Archiving of the documents is only in their analogue form, which means that the digital documents are converted into authorized conversion into analogue forms. The conversions of the documents are done by the paid service Czech POINT. The company has quite good HW and SW equipment for its needs, does the regular maintenance, and this equipment is regularly monitored, restored and modernized.
In this commercial company were found these problematic aspects, which will be necessary to solve in the future:

- time stamp is not used, and it causes the problem for long-term credibility of the digital documents,

- $\quad$ electronic seal is not used, but it could be suitable for signing automatically generating documents,

- the company stores doubled documents (in digital and analogue forms),

- $\quad$ authorized conversions of the forms of documents via Czech POINT is expensive and poorly available,

- credibility and archiving of the old e-mails is not secured enough,

- $\quad$ beginning with archiving documents in the digital form should be taken into account and the same should be done with the digitalization of the present archive.

These realities were found by analyzing the situation in the field of documents dealing in the public administration:

Digital documents are created directly at the office or delivered electronically or in person. This is followed by subsequent operations with them (see Figure no 2).

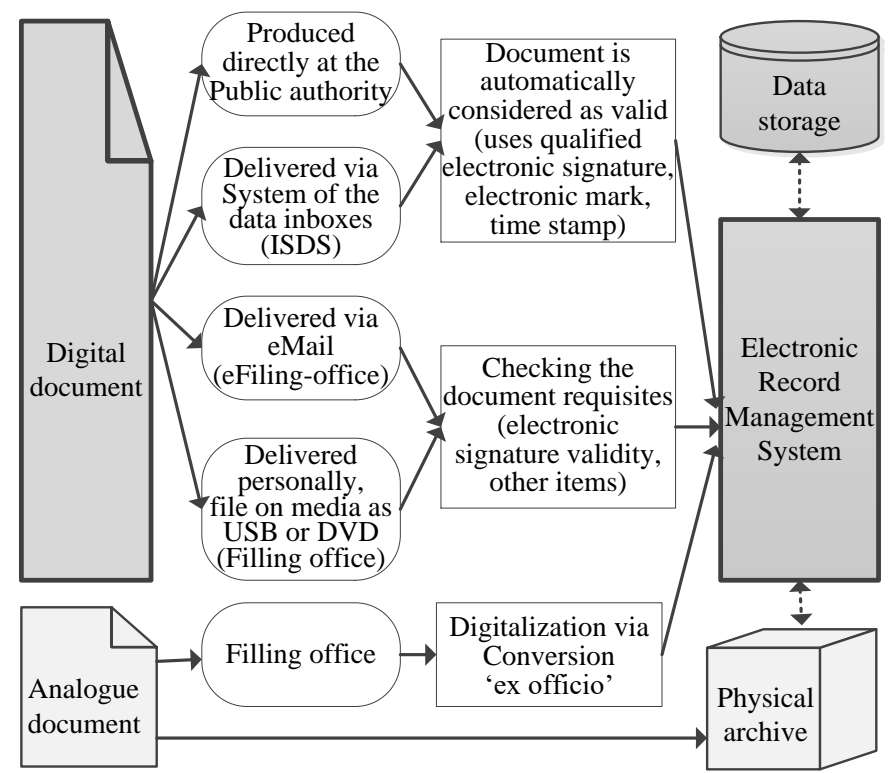

Figure 2. Processing Received and Created Documents; source: own

Legislative rules connected to the eIDAS Regulation meant to do certain changes, which were mainly done within the electronic Record Management System. As the output formats of the digital documents are used the archive format PDF/A. Conversion forms of the documents are done by the own service, which is called the conversion 'ex officio'. The company uses qualified electronic signatures, electronic mark and qualified time stamp. Transactional history of the electronic Records Management is exported to XML documents every day, which is labelled by the electronic mark and time stamp. Thanks to the transactional history of the Records Management is able to ensure the authenticity of the 
digital documents (accepted via ISDS), even without the electronic signature. The company prepares e-shredding through the National Digital Archive.

In this public administration were found these problematic aspects, which needs to be solved in the future:

- qualified electronic seal should be used instead of electronic mark in accordance with the eIDAS Regulation,

- $\quad$ it is necessary to solve how to work with documents in the meantime when the authentication of the system was not used yet,

- it is needed to do shredding procedures,

- $\quad$ archiving must be solved if to use over-stamping of the time stamp or use a different way (e.g. archiving within Record Management System),

- the problem is out dated HW and SW equipment with low capacity.

\section{B. Aspects of Archiving the Digital Documents of the} Companies in the Czech Republic within the Context of the EU eGovernment

We can draw these conclusions on the basis of the problematic of dealing with the digital documents and also on the basis of the investigation in above mentioned companies.

Aspects of archiving of the digital documents come out of the intended length of archiving and also from the type of company (see Figure no 3).

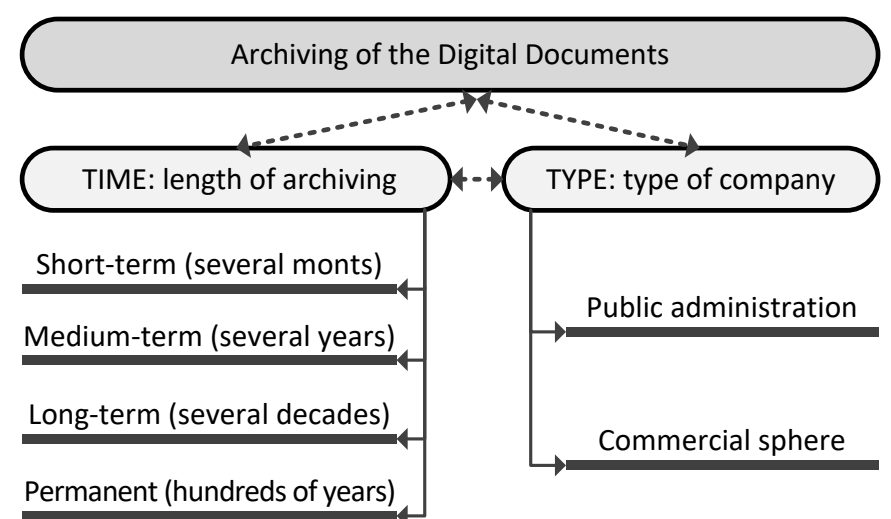

Figure 3. Aspect of Digital Documents Archiving; source: own

\section{Short-term archiving of the digital documents:}

The credibility of the documents is realized by the electronic signature (or seal) of the originator. Absence of the time stamp is not an obstacle for disposable check of the originator of the documents. In the short time it is not necessary to expect the fundamental technological changes, therefore the archiving format does not have to be used for the documents. From the data carrier viewpoint the risk of the documents loss is not high and therefore there are not high demands on maintaining them too much (e.g. by backup).
Overall maintenance of the digital documents in the short-term is minimal only occasional backup is done.

\section{Medium-term archiving of the digital documents:}

For the authenticity security it is necessary to use a combination of the electronic signature (or seal) and time stamp. Using the archiving format is suitable, but not necessary. From the data carrier viewpoint it is necessary to solve the risks connected to the documents loss and pay attention to the backup of the documents.

\section{Long-term archiving of the digital documents:}

The documents validity is necessary to secure, because the archiving time is longer than the validity of the time stamp. In reality it means - to use the transaction log or over-stamp the documents by a new time stamp before the expiry date. From the readability of the documents viewpoint, it is recommended to use archive formats and check of the readability have to be done in case of technological changes. If the fundamental technological or legislative changes will appear, conversions into new formats should be taken into account. In the storage, the regular check and backup is necessary to be done. In summary, it is necessary to maintain the digital documents, to maintain the data carrier and also monitor technological changes within this field.

\section{Permanent archiving of the digital documents:}

Permanent archiving of the digital documents is a basically difficult task. It means to do a regular maintenance not only of the digital documents, but also of the storage. It is necessary to monitor technological changes and adapt the whole archiving process to them. According to the rapid development of the archiving of the digital documents (also from the legislative or technological viewpoint) we should expect many changes in the future. The continuous volume growth of the digital documents forces this field to be developed.

Archiving of the digital documents from the public administration viewpoint:

In the recent times the process of the digitalization of the public administration was significantly shifted and also the archiving of the digital documents connected to it. According to the new legislative changes there is a gradual unification of this process within the EU. In the future it can bring the easier access to the public administration services in the Czech Republic and also in the EU. The extension of this development might help to provide the electronic identity e.g. by the announced electronic ID cards. The main obligation is to secure the credibility of the digital documents for its whole lifetime. Influenced by the cybercrime this task is extremely difficult. It is the reason why the public prefers archiving of the analogue documents to digital ones; it still persists - 'What is on the paper, that is true.'. There is also the economic demand of the overall solution. Initial investment is very high, because the system, which ensures enough either physical or cybercrime safe of the digital documents, is robust (in case of a town hall the investment would be 6 million Czech crowns). 
Archiving of the digital documents from the commercial sphere viewpoint:

Commercial companies are not so bond to the legislation and can use anything what is not forbidden by the law. Therefore it naturally choose the solutions, which are effective and available. From the result of the investigation comes out, that the electronic documents are used more and more often, mainly from the reason of economy, variability, availability, manipulation with the documents and the stability of the quality. In case of the preservation and credibility of the documents, they are converted more and more into analogue documents and archived in the commercial companies, maybe because of the users' immaturity and distrust to the whole process of the digital documents archiving. It is also possible to expect, that by gradual commonplace of the digital documents also the analogue documents will be changed into digital archive. Without a doubt, the economic aspects will be important to the overall solution.

\section{CONCLUSION}

Dealing with digital and analogue documents mean the usage of different technological procedures. However, the reasons for dealing with documents are the same, i.e. the document is always the part of a specific procedure of the organization. The way of dealing the digital document is not stable and is developed all the time, because digital conception of the documents exists only for several decades. Meanwhile the oldest preserved analogue documents (prehistoric mural paintings) are known for several hundreds years. Also the oldest libraries arose three thousands years ago. The computers and digital data did not start before the 20th century and e.g. archive format PDF/A was standardized only ten years ago. The traditional trust in analogue documents is felt in the behavior of the companies (either commercial or public), because they are stored in archive - the digital documents are also transformed into analogue ones for this reason. However, digital documents (and the process of dealing with them) belong to everyday procedures in every company. It is estimated that every year's volume of stored digital data increases by $50 \%$ and about 20 zettabytes of the digital data $(20 * 1021$ bytes) are stored worldwide. Therefore it is important for every company to set and save the procedures for dealing with the digital documents. The solution for dealing with the digital documents is influenced by several proved viewpoints firstly it is the technological solution (e.g. technological principle of electronic signature and the way of implementing), secondly the legislative delimitation is determined (e.g. legal impacts of the documents which is signed by qualified electronic signature) and also the viewpoint of the companies (if it is the commercial organization or public authority), the last viewpoint is the type of the company (if it is the commercial organization or public authority).

In this context, the basic requirements were examined how to secure the readability of the digital documents, how to store and archive them. The requirement of the credibility is solved by standardized formats and possibilities of the documents conversions (conversions between formats and conversions between forms of the documents). The obligation of the standardized formats usage is mainly intended for public administration companies. The commercial companies have this duty only in case of the communication with public administration. The problem is, that the standardized archive format is not 'valid always' which means, that technological development and connected legal changes can establish changes in set formats. Therefore the companies have to watch technological-legislative development and if the changes appear, the companies have to convert the formats and also use the elements for authenticity of the documents. The commercial companies realize the authorized conversions by paid service Czech POINT (a network of assisted public administration centers). Public administration organizations have the right to do the authorized conversions by their own means (conversions 'ex officio').

The requirement of the credibility is solved by the electronic signature (the eIDAS Regulation defines several variants of the signature), electronic seal and electronic time stamp. The question still appears - how to secure the documents to be always valid also after the certificate time expires for the given technological tool (signature, seal, stamp). Supporters of the approach of documents over-stamping necessity in repeated intervals and to make the validity longer by using the new/another time stamp mention the financial expenses connected to the over-stamping.

The over-stamping is necessary at the electronic Records Management, which records the history into transactional log corresponding with the requirements NSESS (National standard for electronic system of the Record Management). Saving and archiving of the digital documents differ from the type of the companies. The commercial companies often use the own data storage or commercial cloud storage. The documents then does not have to be created according to the general standards, and the security of the credibility have to be solved for every document separately. The public administration organizations have to use Record Management System. As it was mentioned above, the long-term archiving of the documents is usually solved by conversions of the digital documents into analogue ones. As it was proved by the investigation in the selected companies, the commercial companies archive the documents only in analogue forms. However, the public administration companies archive the digital documents within Record Management System and also by conversions of the digital documents into analogue ones.

The approach in dealing with the digital documents differs in various types of the companies. Primarily, it does not mean the division of this field into several directions. The development in legislation and technologies should be generalized and popularized as much as possible, so that this field would be easily reached for everybody.

\section{ACKNOWLEDGMENT}

The work reported in this paper was conducted with the kind support of the University Pardubice grant No SGS2019019. 


\section{REFERENCES}

[1] Act No. 235/2004 Coll., on Value-added Tax (o dani z přidané hodnoty), Praha, 2004. [online]. [cit. 2019-03-0s]. Available from WWW <http://www.zakonyprolidi.cz/cs/2004-235>.

[2] Act No. 297/2016 Coll., on trust services for electronic transactions (o službách vytvářejících důvěru pro elektronické transakce), Praha, 2016. [online]. [cit. 2019-03-03]. Available from WWW <http://www.zakonyprolidi.cz/cs/2004-235>

[3] Act No. 300/2008 Coll., eGovernment Act - on Electronic Acts and Authorised Document Conversion, (o elektronických úkonech a autorizované konverzi dokumentů), Praha, 2004. [online]. [cit. 201903-07]. Available from WWW <http://www.zakonyprolidi.cz/cs/2008300>.

[4] Act No. 499/2004 Coll., on archive-keeping and records service (o archivnictví a spisové službě), Praha, 2004. [online]. [cit. 2019-0301]. Available from WWW <http://www.zakony.cz/zakonSB2004499>.

[5] F. Balasa, Data Storage, IntechOpen, 2010. ISBN 978-953-307-063-6, 226 p.

[6] M. Brook, "Data storage lifespans: how long will media really last?", in CIO, 2017. [cit. 2019-02-22]. Available from WWW <https://www.cio.com.au/mediareleases/29049/data-storage-lifespanshow-long-will-media-really/>.

[7] M. Čejka, "eIDAS: Na cestě k digitální důvěře", in Hospodářské Noviny IHNED, 15. 5. 2017, ISSN 1213-7693. [online]. [cit. 2019-0222]. Available from WWW <http://ictrevue.ihned.cz/c3-657288800ICT00_d-65728880-eidas-na->.

[8] Decree No. 259/2012 Coll., on the details of the performance of the file service (o podrobnostech výkonu spisové služby), Praha, 2012. [online]. [cit. 2019-02-01]. Available from WWW <http://www.sagit.cz/info/sb12259ceste-k-digitalni-duvere>.

[9] P. S. Deshpande, S. C. Sharma and S. K. Peddoju, Security and Data Storage Aspect in Cloud Computing, Springer, 2019, 85 p.

[10] J. Donát, M. Maisner and R. Piffl, Nařízení eIDAS: komentáŕ, Praze: C.H. Beck, 2017. ISBN 978-80-7400-633-3, 340 p.

[11] eArchivace, "Archívní formát PDF/A", in EARCHIVACE.CZ 2104. [online]. [cit. 2019-03-03]. Available from WWW <http://www.earchivace.cz/legislativa-a-normy/typy-dokumentu-karchivaci/>.

[12] European Commission, eIDAS Observatory. [online]. [cit. 2019-0303]. Available from WWW <https://ec.europa.eu/futurium/en/ content/eidas-regulation-regulation-eu-ndeg9102014>.

[13] EUR-Lex, "Regulation (EU) No 910/2014 on electronic identification and trust services for electronic transactions in the internal market and repealing Directive 1999/93/EC", in Brusel: Council of the European Union, 2014, no. 910. [online]. [cit. 2019-01-21] Available from WWW <http://eur-lex.europa.eu/legal-content/EN/ALL/?uri=uriserv: OJ.L_.2014.257.01.0073.01.ENG>.

[14] S. Simonova and A. Hudec, "Enterprise content management based on identified requirements", in International Conference on Information and Digital Technologies (IDT), 2015, pp. 324 - 329, 7-9 July 2015 DOI: 10.1109/DT.2015.7222991.

[15] V. Smejkal, J. Kodl and M. Uřičař, "Elektronický podpis podle nařízení eIDAS", in Revue pro právo a technologie, Vol. 6, No. 11, 2015, ISBN 9-771804-538006, p. 189.

[16] J. Smola, Archiving digital documents in an organization (Archivace digitálních dokumentů v organizaci), Supervisor S. Simonova, Pardubice: Univerzita Pardubice, 2018, p. 88. 